HEALTHCARE DELIVERY

\title{
Systems thinking: A turning point for improving respectful obstetric care in South African health districts
}

\author{
S J Oosthuizen, ${ }^{1}$ MB ChB, MMed (Fam Med); A-M Bergh, ${ }^{2}$ PhD; R C Pattinson, ${ }^{2}$ BSc, MB BCh, MMed (O\&G), FCOG (SA), MD, FRCOG \\ ${ }^{1}$ Department of Family Medicine, Faculty of Health Sciences, University of Pretoria, South Africa \\ ${ }^{2}$ South African Medical Research Council Maternal and Infant Health Care Strategies Unit, Faculty of Health Sciences, University of Pretoria, South Africa
}

Corresponding author: S J Oosthuizen (sarie.silberbauer@gmail.com)

Poorly functioning health systems and local health systems barriers affect many women giving birth in low- and middle-income countries. The district clinical specialist teams in South Africa are uniquely positioned to provide facilitation and mentoring during interventions for improving the weak primary healthcare system. To ensure success, four key principles should be considered during scale-up of interventions: systems thinking and awareness of contexts and barriers; a focus on sustainability; harnessing factors known to enhance scalability; and respect for human rights and equity. Asking the right questions about the responsibilities of health systems at the micro-, meso- and macrolevels will benefit scale-up processes and sustain innovative pathways to high-quality obstetric care in communities.

S Afr Med J 2018;108(11):910-914. DOI:10.7196/SAMJ.2018.v108i11.13312

Every woman's access to high-quality obstetric care ${ }^{[1]}$ during childbirth is still not assured in low- and middle-income countries (LMICs). ${ }^{[2,3]}$ More than $70 \%$ of maternal deaths are due to complications of pregnancy and childbirth, while more than $85 \%$ of newborn deaths are attributed to preterm birth, intrapartum perinatal deaths and neonatal infections. ${ }^{[4,5]}$ The Sustainable Developmental Goals set targets at a maternal mortality ratio of $<70$ per 100000 live births and a neonatal mortality rate at least as low as 12 per 1000 live births by $2030 .{ }^{[2]}$

Although the basics of high-impact maternal, newborn and child health interventions are known in LMICs, optimal clinical care is still lagging behind ${ }^{[6]}$ and implementation seldom reaches scale. ${ }^{[6,7]}$ This is the result of poorly functioning health systems, local health systems barriers, ${ }^{[7,8]}$ low and unequitable coverage ${ }^{[3]}$ and problematic political leadership. ${ }^{[9,10]}$ Low political commitment and poor implementation mean that cost-effective innovations fail to reach all groups or the poorer segments of populations in sub-Saharan Africa and LMICs. ${ }^{[1]}$ The effective spread of available strategies for reducing maternal, perinatal, infant and child mortality ${ }^{[2,12]}$ should include a collaborative improvement approach ${ }^{[10,13,14]}$ that incorporates health systems and systems thinking into the pathways of better and sustained care. ${ }^{[15-17]}$

A number of studies have reported on the disrespectful care and mistreatment that some birthing women experience in South African (SA) public health facilities. ${ }^{[18-21]}$ We developed CLEVER, a district-level labour ward package, with scale-up in mind. It is based on a stages-of-change framework and conditions for sustaining the intervention are embedded in the design. ${ }^{[22]}$ All the package components are based on evidence from previously tested interventions in LMICs with positive impact and measured outcomes. The framework of the World Health Organization (WHO) for health systems strengthening and its standards of care and quality statement documents ${ }^{[23-25]}$ informed some of the pathways proposed in CLEVER. The interventions in the package can be individually adapted for the context of each labour ward. The CLEVER package includes the following components: ${ }^{[22]}$

- Clinical care with obstetric triage and handover rounds with risk assessment
- Labour ward management to resolve withholding of care and teamwork issues

- Elimination of barriers through effective communication practices and meeting basic human needs

- Verifying care through nominated champions and monitoring and evaluation

- Emergency obstetric simulation training with capacity building reaching all shifts

- Respectful care to improve mothers' childbirth experiences.

Health systems gaps are addressed on micro-, meso- and macrolevels, while clinical governance is addressed by nominating advanced midwives as unit champions and by involving the facility managers.

Working CLEVER was a three-phased interventional study with a baseline and end-line assessment. We tested it in five midwife-led obstetric units (MOUs) in one district in SA in 2016. Five other MOUs served as the control group. Over the period 2015 - 2017, outcome measurements showed statistically significant improvements in key perinatal output indicators in the MOUs where the package was implemented. Intrapartum-related stillbirths were reduced from 8.36 to 0.49 per 1000 births in the intervention MOUs, compared with a reduction from 8.33 to 2.61 in the control group ( $p=0.003$ ). The incidence of birth asphyxia was reduced from 13.09 to 5.19 per 1000 live births in the intervention group and increased from 7.41 to 9.70 per 1000 in the control group $(p=0.002)$. Meconium aspiration decreased from 11.98 to 3.71 per 1000 live births in the intervention group and from 3.46 to 2.62 in the control group ( $p=0.003$ ).

The intervention should now be tested in district hospital labour wards. The ideal facilitators for implementing this intervention are district clinical specialist teams (DCSTs). These were appointed in $2012^{[26]}$ as one of three streams in the SA national primary healthcare (PHC) re-engineering strategy to address a weak PHC system ${ }^{[27]}$ and to ensure effective clinical governance, risk management and quality improvement processes. ${ }^{[28]}$ DCST members are integrated in the health system and their salaries are covered. Improvement in health system gaps could be financed from existing budgets if there is appropriate justification for proposed expenses. Doing 
an intensive 3-month outreach with the CLEVER intervention may incur additional expenses such as travel costs and the printing of material. However, it could be argued that an improvement in quality of care may lead to substantial savings for the health system, inter alia because of a potential drop in litigation cases.

The aim of this discussion is to stimulate thinking on how the findings from the implementation of an evidence-informed intervention package could inform policymaking with regard to scaling up the intervention to other districts in SA. This discussion draws on the 2012 series on systems thinking published in Health and Policy Planning, ${ }^{[10,16,17,29-31]}$ and the WHO work on health systems building blocks, ${ }^{[11]}$ scaling-up strategies ${ }^{[25]}$ and criteria for quality standards. ${ }^{[24]}$

\section{Four key principles for scalling up the CLEVER package}

For scaling up the CLEVER package, we identified four key principles proposed by the WHO to be included in any planning and roll-out: systems thinking; a focus on sustainability; harnessing factors known to enhance scalability; and respect for human rights and equity. ${ }^{[25]}$

1. Systems thinking implies working with a dynamic complexity of networks, interactions and relationships. This interconnectedness and interdependence is also illustrated by the facility environment of MOUs. Midwifery teams have to find a balance between different actions that could create networks and relationships. These interactions produce either a favourable or a negative response. ${ }^{[16]}$ The same would apply to district hospitals.

2. Focus on sustainability refers to the collaborative way ${ }^{[13]}$ in which policy, programme development and the available budget can constrain or support a process. ${ }^{[25]}$ Sufficiently skilled midwives, and adequate supplies of drugs, equipment and support services, are essential for programme expansion and sustainability.

3. Any review of the scalability of an intervention and ways to enhance it should be based on the previous determinants of success during the implementation phase of an innovation. ${ }^{[25]}$ The strategy of nominating leader midwives or champions as role models to roll out CLEVER in participating labour wards could enhance the scalability of the intervention, ${ }^{[22]}$ while facility manager support provides accountability.

4. Lastly, the promotion and upholding of human rights and equity for all should be the common goal in the scaling up of interventions. ${ }^{[32]}$ In our feedback processes to improve caring practices, we must advocate for patient-centred approaches in health facilities, with attention to respecting cultural differences and equitable access and care for minority groups. ${ }^{[25]}$ Midwife-led teams need to share the vision of respectful care and should be enabled to develop capacities for co-ordinated action and change. ${ }^{[33]}$

\section{Complex adaptive systems in scalle-up initiatives}

To be able to scale up 'working CLEVER', it is important to understand how the SA health system functions as a complex adaptive system. Any discussion on scaleup should acknowledge that health systems are embedded in a bigger system and are influenced by social, political and economic systems. Community characteristics determine health needs, and the health system should respond with appropriate resources in order to create equal access to healthcare. ${ }^{[34]}$ These aspects would therefore also influence interventions and their scaleup. We illustrate the complexity of the health system and the interactions at play during the implementation of an intervention in one MOU in two diagrams. In Fig. 1 we start with an overview of the different levels of the SA health system involved in the scale-up of any new intervention. There are bidirectional interactive pathways from the national macro-level to the subdistrict micro-level to the level of individual MOUs and the district hospital.

Fig. 1 explains how the DCSTs as stewards $^{[23]}$ and integrators ${ }^{[32]}$ of the implementation framework should follow

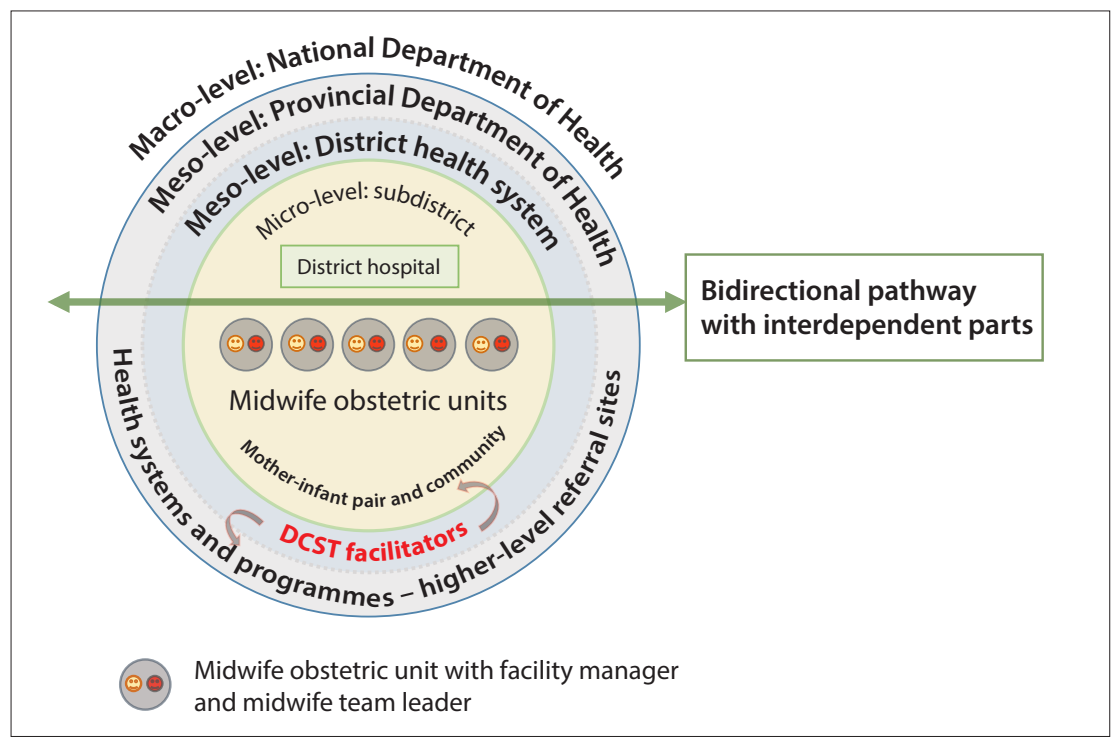

Fig. 1. Complex adaptive systems in scaling up respectful obstetric care. $(D C S T=$ district clinical specialist team.)

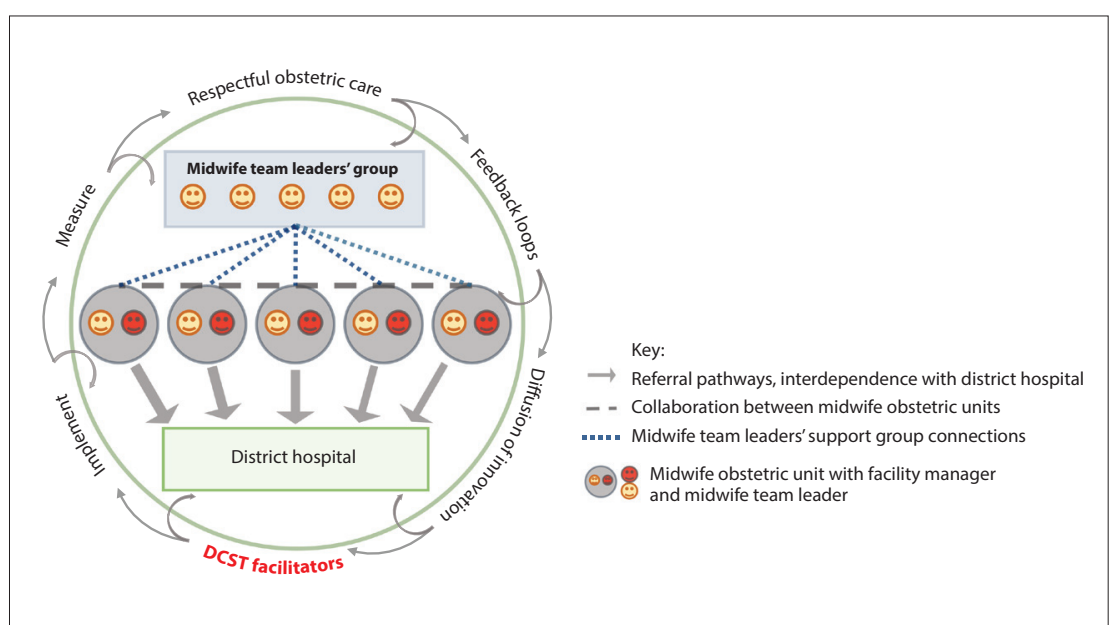

Fig. 2. Midwife obstetric units as scale-free hubs in the health system. (DCST = district clinical specialist team.) 


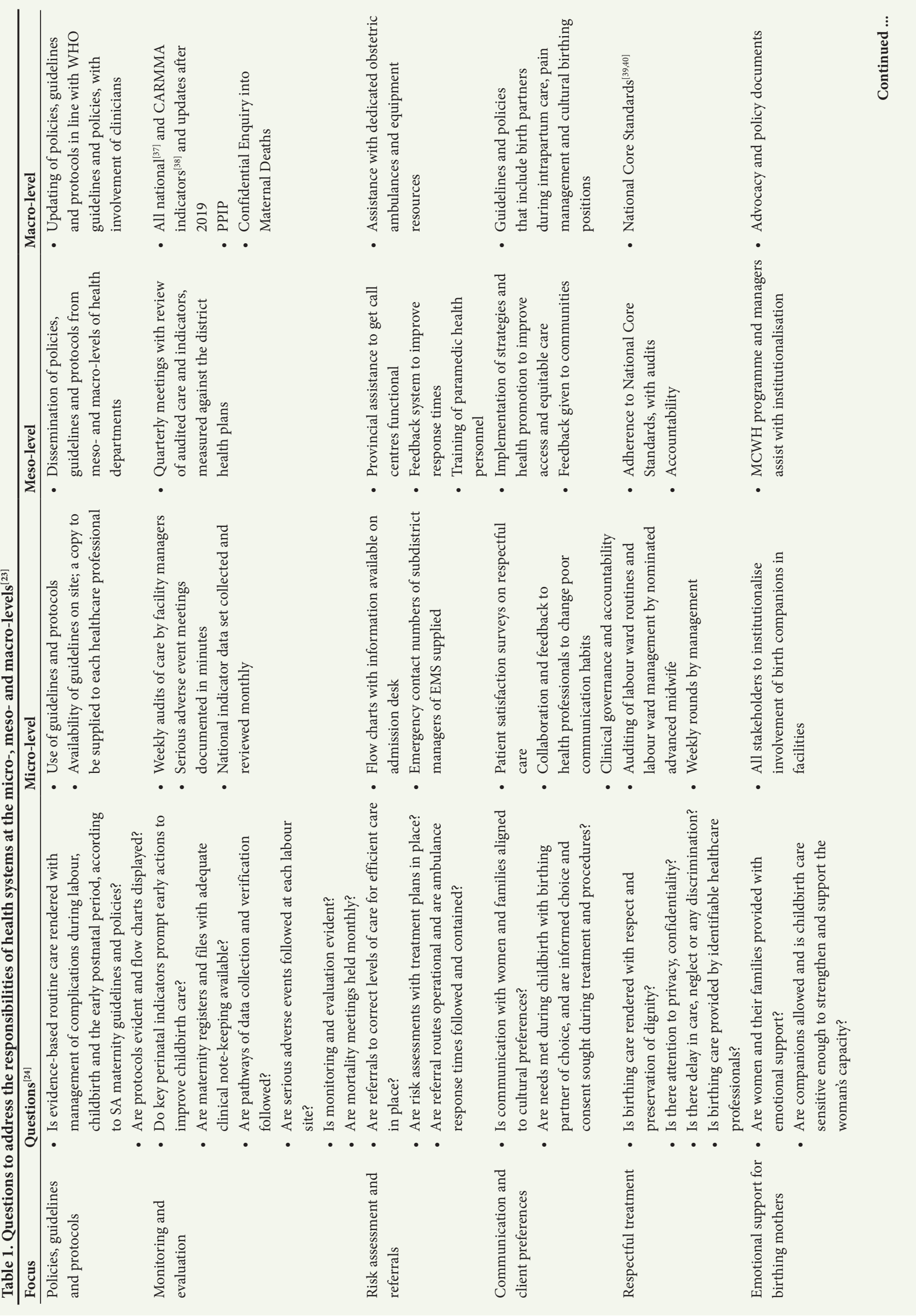




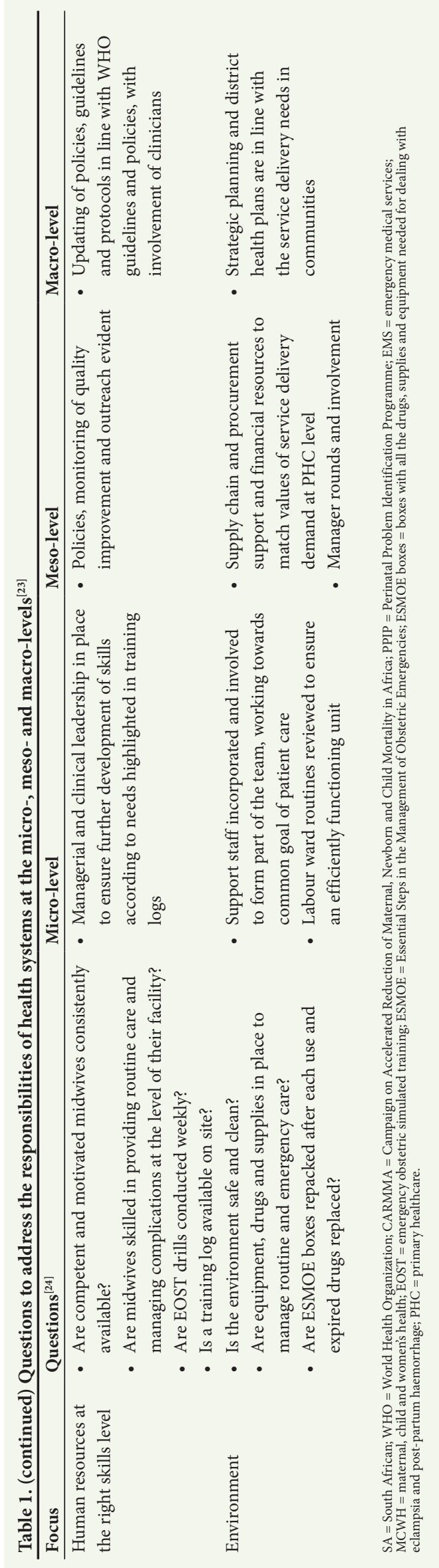

a health systems thinking pathway that includes positive feedback ${ }^{[10,30]}$ and champions. ${ }^{[35]}$ Collaboration and the acknowledgement of interdependence could break down existing barriers and resistance to change at local sites and assist with the integration of services in a larger network. These interactions can have a domino effect and produce change in the bidirectional pathways. ${ }^{[30]}$ The scale-up of CLEVER should take place from the micro-levels upwards and should not be imposed from above. This should be accompanied by clinical governance and feedback structures through all levels of the health system. ${ }^{[13,17,30]}$ This framework can address causes of poor performance and includes coalition building, tools for implementation and accountability. ${ }^{[36]}$

During the 'working CLEVER' study, the MOUs provided insight into collaboration, networking and the implementation of the intervention. Fig. 2 illustrates how MOUs and the district hospitals act as 'scale-free hubs. ${ }^{[30]}$ This means that they do not only liaise with each other through collaboration and networking, but also with elements in the community and the social, political and economic systems.

\section{Asking the right questions}

The issues highlighted in the WHO standards for maternal and newborn care in health facilities ${ }^{[24]}$ and in its scale-up strategy ${ }^{[25]}$ should be applied to all the interdependent parts in the pathway and all stakeholders should be included. This entails asking the right questions that could enhance the scale-up strategy embedded in the CLEVER package. In Table 1 we give an overview of a set of focused questions and scale-up strategies. ${ }^{[24,25]}$ In addition, we include information on what should be done where and by whom at the micro-, meso- and macro-levels of the health system. These questions and the breakdown according to the different levels of care could provide guidance on strategies and policies needed to assist in the implementation and scaling up of CLEVER in SA's district-level health facilities. To enhance policy-making, questions based on the desired background in district hospital labour wards and referral MOUs should identify the barriers in these wards. This would assist in tailoring context-specific health systems strengthening as part of the start-up to implement the intervention. In a complex intervention we need to address gaps in multiple health systems building blocks ${ }^{[23]}$ and sub-level changes simultaneously to facilitate implementation and improve reports on the important effects on the system. The questions asked would relate to the functioning of complex adaptive health systems and could lead to improvements in perinatal mortality and morbidity and of women's experiences of childbirth. A reduction in mortality rates reflects timely, highquality care during childbirth and progress in the responsiveness of the health system to take appropriate action. ${ }^{[31]}$

Successful scale-up actions should include health systems strengthening across all building blocks and should apply to service delivery, the health workforce, health information systems, access to essential medicines, financing, and leadership and governance. ${ }^{[41]}$ To be able to scale innovations, health systems governance needs the complex and multidimensional approach of systems thinking. The characteristics of complex systems and human behaviour should undergo a process of adaptation during implementation, with a focus on local barriers and attention to any unintended outcomes. ${ }^{[31]}$ We can bring respectful, high-quality obstetric care back into communities through health systems strengthening and the improvement of midwifery skill and capabilities. This should be matched with leadership, clinical governance and accountability ${ }^{[42]}$ at the micro-, meso- and macro-levels to bring about the turning point.

\section{Conclusion}

The CLEVER intervention should now be rolled out to other MOUs and tested in district hospitals in SA. Following the bidirectional pathways in the health system and strengthening the system could make the long-term vision of highquality respectful obstetric care to birthing women attainable and could sustain the innovation.

The three key messages related to health systems thinking that emerged from the CLEVER intervention are the following: 
- Collaboration with feedback should ensure that the kind of care that birthing women expect during labour matches the care that midwives provide.

- Interprofessional teamwork linking different levels of the health system should provide one standard of care, regardless of where women give birth.

- Promoting strong clinical governance and accountability and ensuring dedicated, motivated and skilled birth attendants will create the turning point.

Declaration. This publication is part of the $\mathrm{PhD}$ studies of the first author, SJO. Acknowledgements. The authors thank the healthcare professionals and clients who participated in the intervention. Special thanks go to Ute Feucht, Hannelie Venter and Peter Macdonald for reading and commenting on earlier drafts of the manuscript.

Author contributions. SJO, AMB and RCP participated in the design of the study to develop and test the CLEVER package. SJO wrote the first draft of the paper, on which AMB and RCP made extensive comments.

Funding. The South African National Department of Health and the South African Medical Research Council Unit for Maternal and Infant Health Care Strategies, University of Pretoria, provided financial support for the development and testing of the CLEVER package. The Department of Family Medicine, University of Pretoria, provided a research assistant. The funders played no further role in any part of the research.

Conflicts of interest. None.

1. World Health Organization. Quality of Care: A Process for Making Strategic Choices in Health Systems. Geneva: WHO, 2006. http://apps.who.int/iris/bitstream/handle/10665/43470/9241563249_ eng.pdf? sequence $=1$ \&isAllowed $=y$ (accessed 23 March 2018).

2. World Health Organization. Health in 2015: From MDGs to SDGs. Geneva: WHO, 2015. http://www. who.int/gho/publications/mdgs-sdgs/en/ (accessed 23 March 2018).

3. Dickson KE, Simen-Kapeu A, Kinney MV, et al. Every newborn: Health-systems bottlenecks and strategies to accelerate scale-up in countries. Lancet 2014;384(9941):438-454. https://doi.org/10.1016/ S0140-6736(14)60582-1

4. Say L, Chou D, Gemmill AW, et al. Global causes of maternal death: A WHO systematic analysis. Lay L, Chou D, Gemmill AW, et al. Global causes of maternal death: A WHO systematic
Lancet Glob Health 2014;2(6):e323-e333. https://doi.org/10.1016/S2214-109X(14)70227-X

Lancet Glob Health 2014;2(6):e323-e333. https://doi.org/10.1016/S2214-109X(14)70227-X
5. Liu L, Oza S, Hogan D, et al. Global, regional, and national causes of child mortality in 2000-13, 5. Liu L, Oza S, Hogan D, et al. Global, regional, and national causes of child mortality in 2000-13,
with projections to inform post-2015 priorities: An updated systematic analysis. Lancet with projections to inform post-2015 priorities: An updated sy
2015;285:(9966):430-440. https://doi.org/10.1016/S0140-6736(14)61698-6

6. Heiby J, Armbruster D, Jacobs T. Better care for every patient, every time: Improving quality in low health systems. BJOG 2014;121(Suppl 4):4-7. https://doi.org/10.1111/1471-0528.12903

7. Stokes T, Shaw EJ, Camosso-Stefinovic J, et al. Barriers and enablers to guideline implementation strategies to improve obstetric care practice in low- and middle-income countries: A systematic review of qualitative evidence. Implement Sci 2016;11:144. https://doi.org/10.1186/s13012-016-0508-1

8. Abuya T, Ndwiga C, Ritter J, et al. The effect of a multi-component intervention on disrespect and abuse during childbirth in Kenya. BMC Pregnancy Childbirth 2015;15:224. https://doi.org/10.1186/ s12884-015-0645-6

9. Thomas LS, Jina R, Tint KS, et al. Making systems work: The hard part of improving maternal health services in South Africa. Reprod Health Matters 2007;15(30):38-49. https://doi.org/10.1016/S09688080(07)30314-5

10. Willis C, Riley B, Best A, Ongolo-Zogo P. Strengthening health systems through networks: The nied for measurement and feedback. Health Policy Plan 2012;27(Suppl 4):iv62-iv66. https://doi.
need org/10.1093/heapol/czs089

11. Bhutta SZ, Chopra M, Axelson H, et al. Countdown to 2015 decade report (2000-10): Taking stock of maternal, newborn, and child survival. Lancet 2010;375(9730):2033-2044. https://doi.org/10.1016/ S0140-6736(10)60678-2

12. Tunçalp Ö, Were WM, MacLennan C, et al. Quality of care for pregnant women and newborns - the WHO vision. BJOG 2015;122(8):1045-1049. https://doi.org/10.1111/1471-0528.13451

13. Franco L, Marquez L. Effectivenes of collaborative improvement: Evidence from 27 applications in 12 less-developed and middle-income countries. BMJ Qual Saf 2011;20(8):658-665. https://doi. org $/ 10.1136 /$ bmjqs. 2010.044388

14. Ten Hoope-Bender P, de Bernis L, Campbell J, et al. Improvement of maternal and newborn health through midwifery. Lancet 2014;384(9949):1226-1235. https://doi.org/10.1016/S0140-6736(14)60930-2

15. Ten Hoope-Bender P, Lopes S, Nove A. Midwifery 2030: A woman's pathway to health. What does this mean? Midwifery 2016;32:1-6. https://doi.org/10.1016/j.midw.2015.10.014
16. Atun R. Health systems, sytems thinking and innovation. Health Policy Plan 2012(Suppl 4);27:iv4-iv8. https://doi.org/10.1093/heapol/czso88

17. Adam T, de Savigny D. Systems thinking for strengthening health systems in LMICs: Need for paradigm shift. Health Policy Plan 2012;27(Suppl 4):iv1-iv3. https://doi.org/10.1093/heapol/czs084
parting

18. Honikman S, Fawcus S, Meintijes I. Abuse in South African maternity settings is a disgrace: Potential solutions to the problem. S Afr Med J 2015;105(4):284-286. https://doi.org/10.7196/SAMJ.9582
solitis

19. Jewkes R, the problem. S Afr Med J 2015;105(4):284-286. https://doi.org/10.7196/SAM].9582 Jewkes R, Abrahams N, Mvo Z. Why do nurses abuse p
obstetric services. Soc Sci Med 1998;47(11):1781-1795.

20. Chadwick RJ, Cooper D, Harries J. Narratives of distress about birth in South African public maternity settings: A qualitative study. Midwifery 2014;30(10):862-868. https://doi.org/10.1016/j midw.2013.12.014

21. Jewkes R, Penn-Kekana L. Mistreatment of women in childbirth: Time for action on this importan dimension of violence against women. PloS Med 2015;12(6):e1001849. https://doi.org/10.1371/ journal.pmed

22. Oosthuizen SJ, Bergh AM, Grimbeek J, Pattinson R. Midwife-led obstetric units working 'CLEVER' Improving perinatal outcome indicators in a South African health district. S Afr Med J (in press).

23. World Health Organization. Everybody's Business: Strengthening Health Systems to Improve Health Outcomes. WHO's Framework for Action. Geneva: WHO, 2007. http://apps.who.int/iris/bitstream/ handle/10665/43918/9789241596077 eng.pdf;jsessionid=44D0637590F3446CEF91ABBE1F0DBFB0? sequence $=1$ (accessed 23 March 2018).

24. World Health Organization. Standards for Improving Quality of Maternal and Newborn Care in Health Facilities. Geneva: WHO, 2016. http://apps.who.int/iris/bitstream/hand Care in Health Facilities. Geneva: WHO, 2016. http://apps.who.int/is/
le/10665/249155/9789241511216-eng.pdf?sequence $=1$ (accessed 23 March 2018).

25. World Health Organization. ExpandNet. Nine steps for developing a scaling-up strategy. 2010. http:// World Health Organization. ExpandNet. Nine steps for developing a scaling-up strategy. 2010. http://
expandnet.net/PDFs/ExpandNet-WHO20\%Nine\%20Step\%20Guide\%20published.pdf (accessed 28 expandnet.net/PD
September 2017).

26. Ministerial Task Team. District clinical specialist teams in South Africa: Ministerial task team report to the Honourable Minister of Health, Dr Aaron Motsoaledi. 2012. http://www.google.co.za/

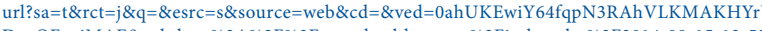
DxgQFggjMAE\&url=http\%3A\%2F\%2Fwww.health.gov.za\%2Findex.php\%2F2014-08-15-12-5504\%2Fcategory\%2F100-2012rp\%3Fdownload\%3D186\%3Adistrict-clinical-specialist-teams-in-southafrica-ministerial-task-team-report\&usg=AFQjCNFf4InCkNYzBB5uyOAFB1wdR3A0fw (accessed 30 January 2018)

27. Naledi T, Barron P, Schneider H. Primary health care in SA since 1994 and implications of the new vision for PHC re-engineering. In: Padarath A, English R, eds. South African Health Review 2011. Durban: Health Systems Trust, 2011:17-28. http://www.hst.org.za/publications/South\%20African\%20 Health\%20Reviews/sahr_2011.pdf (accessed 23 March 2018).

28. National Department of Health. Handbook for District Clinical Specialist Teams (DCST). Pretoria NDoH, 2014. https://www.health-e.org.za/wp-content/uploads/2015/06/Handbook-for-DCSTs.pd (accessed 23 March 2018)

29. Swanson R, Cattaneo A, Bradley E, et al. Rethinking systems strengthening: Key system thinking tools and strategies for transformational change. Health Policy Plan 2012;27(Suppl 4):iv54-iv61. https://doi. org/10.1093/heapol/czs090

30. Paina L, Peters D. Understanding pathways for scaling up health services through the lens of complex Paina L, Peters D. Understanding pathways for scaling up health services through the lens of com
adaptive systems. Health Policy Plan 2012;27(5):365-373. https://doi.org/10.1093/heapol/czr054

31. Adam T, Hsu J, de Savigny D, et al. Evaluating health system strenghtening interventions: Are we asking the right questions? Health Policy Plan 2012;27(Suppl 4):iv9-iv19. https://doi.org/10.1093/ asking the righ
heapol/czs086

32. Berwick DM, Nolan TW, Whittington J. The triple aim: Care, health, and cost. Health Aff 2008;27(3):759-769. https://www.healthaffairs.org/doi/pdf/10.1377/hlthaff.27.3.759 (accessed 4 October 2018

33. Senge PM. The Fifth Discipline: The Art and Practice of the Learning Organisation. London: Random House Business Books, 2006

34. Anderson L, Scrimshaw S, Fullilove M, et al. The community guide's model for linking the social environment to health. Am J Prev Med 2003;24(3, Suppl):12-20. https://doi.org/10.1016/S0749$3797(02) 00652-9$

35. Raven J, Hofman J, Adegoke A, et al. Methodology and tools for quality improvement in materna and newborn care. Int J Gynaecol Obstet 2011;114(1):4-9. https://doi.org/10.1016/.ijgo.2011.02.007

36. Anand S, Ammar W, Evans T, et al. Report of the Scientific Peer Review Group on Health System Performance Assessment: Debates, Methods and Empiricism. Geneva: World Health Organization, 2003:839-913.

37. Pattinson RC, Rhoda N. Saving babies 2012 - 2013: Ninth Report on Perinatal Care in South Africa. Pretoria: Tshepisa Press, 2014. https://www.ppip.co.za/wp-content/uploads/Saving-Babies-2012-2013. Pretoria: Thepisa Press, 2014.
pdf (accessed 23 March 2018).

38. National Department of Health, South Africa. South Africa’s National Strategic Plan for Campaign on Accelerated Reduction of Maternal and Child Mortality in Africa (CARMMA). Pretoria: NDoH, 2012. http://www.kznhealth.gov.za/family/CARMMA_South_Africa_Strategy.pdf (accessed 23 March 2018).

39. National Department of Health, South Africa. Ideal Clinic Definitions, Components and Checklists. National Department of Health, South Africa. Ideal Clinic Definitions, Components and Checklists.
Pretoria: NDoH, 2017. https://www.idealclinic.org.za/docs/v17/Final\%20Ideal\%20Clinic\%20 Framework\%20-\%20version\%2017\%20on\%203\%20Aug\%202017.pdf (accessed 23 March 2018).

40. National Department of Health, South Africa. National Guideline on Conducting Patient Experience of Care Surveys in Public Health Establishments. Pretoria: NDoH, 2017. https://www.idealclinic.org. $\mathrm{za} /$ docs/guidelines/National $\% 20$ Guideline $\% 20$ to $\% 20$ conduct $\% 20$ Patient $\% 20$ Experience $\% 20 \mathrm{of} \% 20$ Care\%20Surveys\%20Oct\%202017.pdf (accessed 23 March 2018).

41. Pyone T, Smith H, van den Broek N. Frameworks to assess health sytems governance: A systematic review. Health Policy Plan 2017;32(5):710-722. https://doi.org/10.1093/heapol/czx007

42. Mutale W, Ayles $\mathrm{H}$, Bond V, et al. Application of systems thinking: 12-month postintervention evaluation of a complex health system intervention in Zambia: The case of the BHOMA. J Eval Clin Pract 2017;23(2):439-452. https://doi.org/10.1111/jep. 12354

Accepted 29 May 2018 